\title{
Network of microRNA, transcription factors, target genes and host genes in human mesothelioma
}

\author{
GUANHUA ZHANG ${ }^{1,2}$, ZHIWEN XU ${ }^{1-3}$ and NING WANG ${ }^{2,3}$ \\ ${ }^{1}$ Department of Software Engineering; ${ }^{2}$ Key Laboratory of Symbol Computation and Knowledge Engineering of \\ the Ministry of Education; ${ }^{3}$ Department of Computer Science and Technology, \\ Jilin University, Changchun, Jilin 130012, P.R. China
}

Received April 21, 2015; Accepted May 16, 2016

DOI: $10.3892 /$ etm.2017.4296

\begin{abstract}
Significant progress has been made into the elucidation of the etiology of mesothelioma at the level of the genes and miRNA. Nevertheless, researchers in this field remain unable to systematically construct a network that demonstrates the specific relationships between genes, miRNA and transcription factors (TFs). TFs are key regulatory elements that control gene expression. In the present study, according to the transcriptional regulatory rule, three regulatory networks were constructed using experimentally validated elements to explore the pathogenesis of mesothelioma. We focused on the regulatory relationship between the miRNA and its host gene, the miRNA and its target gene, and the miRNA and TFs. Expressed, related and global networks were constructed, and the similarities and differences between them were analyzed. Notably, the differentially expressed network used in the present study, which was based on experimentally validated data, contained numerous incorrect expression signal pathways for the pathogenesis of mesothelioma. In theory, if these errors are corrected, this cancer may be prevented or cured. Subsequent analysis of the differentially expressed nodes and pathways may help to explain the pathogenesis of mesothelioma. Notably, some of these exhibited a self-adaption relationship, which was detected by listing the upstream and downstream elements in a table with differentially expressed genes and miRNA. The findings of the present study demonstrated detailed transcriptional regulation, which may serve as
\end{abstract}

Correspondence to: Professor Zhiwen Xu, Department of Computer Science and Technology, Jilin University, 2699 Qianjin Street, Changchun, Jilin 130012, P.R. China

E-mail: xuzw@jlu.edu.cn

Abbreviations: miRNA, microRNA; TFs, transcription factors; Targets, target genes; TFBSs, transcription factor binding sites; NCBI, National Center for Biotechnology Information

Key words: transcription factors, microRNA, target genes, host gene, network, mesothelioma a reference to aid further elucidation of the pathogenesis of mesothelioma.

\section{Introduction}

Mesothelioma is a rare type of human cancer which arises in mesothelial cells covering certain parts of the body. The most common anatomical site for mesothelioma is the pleura, which forms the outer lining of the lungs and internal chest wall. Mesothelioma can also develop in the peritoneum, which is the lining of the abdominal cavity, the pericardium or the tunica vaginalis (1). The majority of individuals who have worked as miners suffer from mesothelioma, as they have inhaled or ingested asbestos fibers and live with the danger of exposure to airborne asbestos dust and fibers (2).

Previous experimentation has demonstrated that differentially expressed genes (DEGs) and miRNA have an effect on the development, metastasis and therapy of mesothelioma (3). Although the DEGs and miRNA associated with mesothelioma have been elucidated, a detailed mechanism of the transcriptional regulation of mesothelioma is yet to be clarified (4). Furthermore, the related genes and miRNA of mesothelioma have fewer roles than the differentially expressed factors (5).

Transcription factors (TFs) and miRNA are prominent regulators of gene expression (6). TFs are proteins that bind to a specific DNA sequence to regulate gene expression. They function as activators or repressors alone or in cooperation, which results in the upregulation or downregulation of the transcription of neighboring genes (1). miRNA are small non-coding RNA molecules that also regulate gene expression at the post-transcriptional level; therefore, they have fundamentally important roles in mesothelioma.

Previous studies have demonstrated that miRNA target genes that regulate various biological processes, which has provided a database consisting of large amounts of experimentally validated data (7-13). The genes that miRNA are located on are referred to miRNA host genes. Rodriguez et al (14) indicated that miRNA are transcribed in parallel with their host transcripts and two different transcription classes of miRNA, exonic and intronic, were identified. Baskerville et al (15) demonstrated that intronic miRNA and its host gene are closely related. In the present study, when discussing differentially expressed miRNA, we considered its host genes to be mutated. 
In the present study, experimentally validated data on differentially expressed factors and related factors were manually collated from various literature sources and databases. These experimentally validated relations concerned genes regulating miRNA and miRNA located on host genes or targeting target genes. These regulatory relations were chosen as they were considered them to be a basic resource for the construction of three networks to reveal the regulatory mechanism in mesothelioma. The three regulatory networks were as follows: i) DEGs and miRNA; ii) predominantly related genes and miRNA; and iii) a global network constructed from all data associated with mesothelioma. Nodes and pathways in three networks were analyzed in order to identify those with valuable regulatory relationships in mesothelioma. The findings of the present study may aid further elucidation of the pathogenesis of mesothelioma.

\section{Materials and methods}

Mutated genes in mesothelioma. Data on mutated genes were collected from the National Center for Biotechnology Information single nucleotide polymorphism database (ncbi.nlm.nih.gov/snp/), Cancer Genetics Web (cancerindex.org/geneweb/index.html), the Science Citation Index and the Kyoto Encyclopedia of Genes and Genomes pathway database (genome.jp/kegg/pathway.html).

Related genes in mesothelioma. Data on all the genes related to mesothelioma were collected via three methods. Firstly, the SCI papers about mesothelioma were reviewed to collect the names of the genes related to mesothelioma. Secondly, the related genes were searched on the GeneCards database (genecards.org/) (16), and the genes ranked within the top 200 were saved. Thirdly, popular TFs were identified using the P-match method (17). The steps were as follows: 1,000 nt promoter region sequences of the targets of DEGs were downloaded from the UCSC database (genome.ucsc.edu/) (18), and the P-match method was subsequently used, as it combines pattern matching and weight matrices approaches to identify TF binding sites (TFBSs) in 1,000 nt promoter region sequences and maps the TFBSs onto promoter regions of targets. These TFs found by P-Match were also added to the file, as were mutated genes of mesothelioma.

Differently expressed miRNA in mesothelioma. Differentially expressed miRNA were extracted from a manually curated database named mir2Disease (mir2disease.org/), which catalogues differentially expressed miRNA in various human diseases (19). Some miRNA were also located in the SCI literature using a keywords search for 'mir'.

miRNA-targets dataset. Tarbase 5.0 (http://diana.imis. athena-innovation.gr/DianaTools/index.php?r=tarbase/index) and miRTarBase (mirtarbase.mbc.nctu.edu.tw/) databases were used to collate the whole human miRNA and their target genes. Official NCBI (www.ncbi.nlm.nih.gov/gene/) miRNA and gene symbols were used. This dataset was assigned as $U_{1}$.

TF-miRNA dataset. Using the TransmiR database (cmbi.bjmu.edu.cn/transmir/) data on the associations between TFs and miRNA were collated (20). The TransmiR database catalogues data extracted from public literature and biological experiments. This dataset was assigned as $U_{2}$.

miRNA-host gene dataset. Data on the host genes of human miRNA were manually extracted from miRBase (mirbase.org/) and NCBI (21). Subsequently, their official symbols and IDs were unified to those outlined by NCBI. This dataset was assigned as $U_{3}$.

\section{Construction of three level networks.}

Differentially expressed network of mesothelioma. DEGs and miRNA are genes that are not properly expressed. Their misregulation directly leads to the formation of mesothelioma; therefore, each node and pathway was examined. As outlined, the obtained mutated factors were assigned as the nodes in the network. Subsequently, these nodes were mapped onto the $U_{1}, U_{2}$ and $U_{3}$ datasets to extract the regulatory relation as the edges in the network. After all relationships were combined, the core misregulation network of mesothelioma was established.

Related network of mesothelioma. The function of related factors, which also affect regulatory relationships, should not be neglected. Therefore, a network of related genes and miRNA was constructed to further elucidate the regulatory mechanism of mesothelioma. Certainly, it contains more regulatory relations than the core network. The construction of this network was similar to the differentially expressed network. The related elements were mapped onto $U_{1}, U_{2}$ and $U_{3}$, and the regulatory relationships among TF, targets and host genes associated with miRNA in mesothelioma were subsequently extracted.

Global network of mesothelioma. In the third network, all the obtained genes and miRNA were mapped onto $U_{1}, U_{2}$ and $U_{3}$, and the regulatory relationships among TF-miRNA, target-miRNA and host-miRNA were extracted. Following integration of all the relationships, the global network of mesothelioma was established.

\section{Results and Discussion}

Differentially expressed network of mesothelioma. Fig. 1 presents the important regulatory relationships of differentially expressed factors in mesothelioma, composed of five TFs [tumor protein 53 (TP53), phosphatase and tensin homolog (PTEN), E2F1, nuclear factor of kappa light polypeptide gene enhancer in B-cells 1 (NFKB1) and epidermal growth factor reception (EGFR)], nine targets of miRNA, and 31 miRNA and their host genes. The nodes were all experimentally validated and differentially expressed, with the exception of their host genes. Notably, TP53 and PTEN genes are mutated in various cancers (22). For instance, TP53 typically acts as a tumor suppressor gene which influences apoptosis and inhibits proliferation in cancer (23). As demonstrated in Fig. 1, a host gene may include one or several miRNA which may target other genes. For example, MIR31 is the host gene for hsa-miR-31, whereas hsa-miR-31 targets large tumor suppressor kinase 2. miRNA be located 


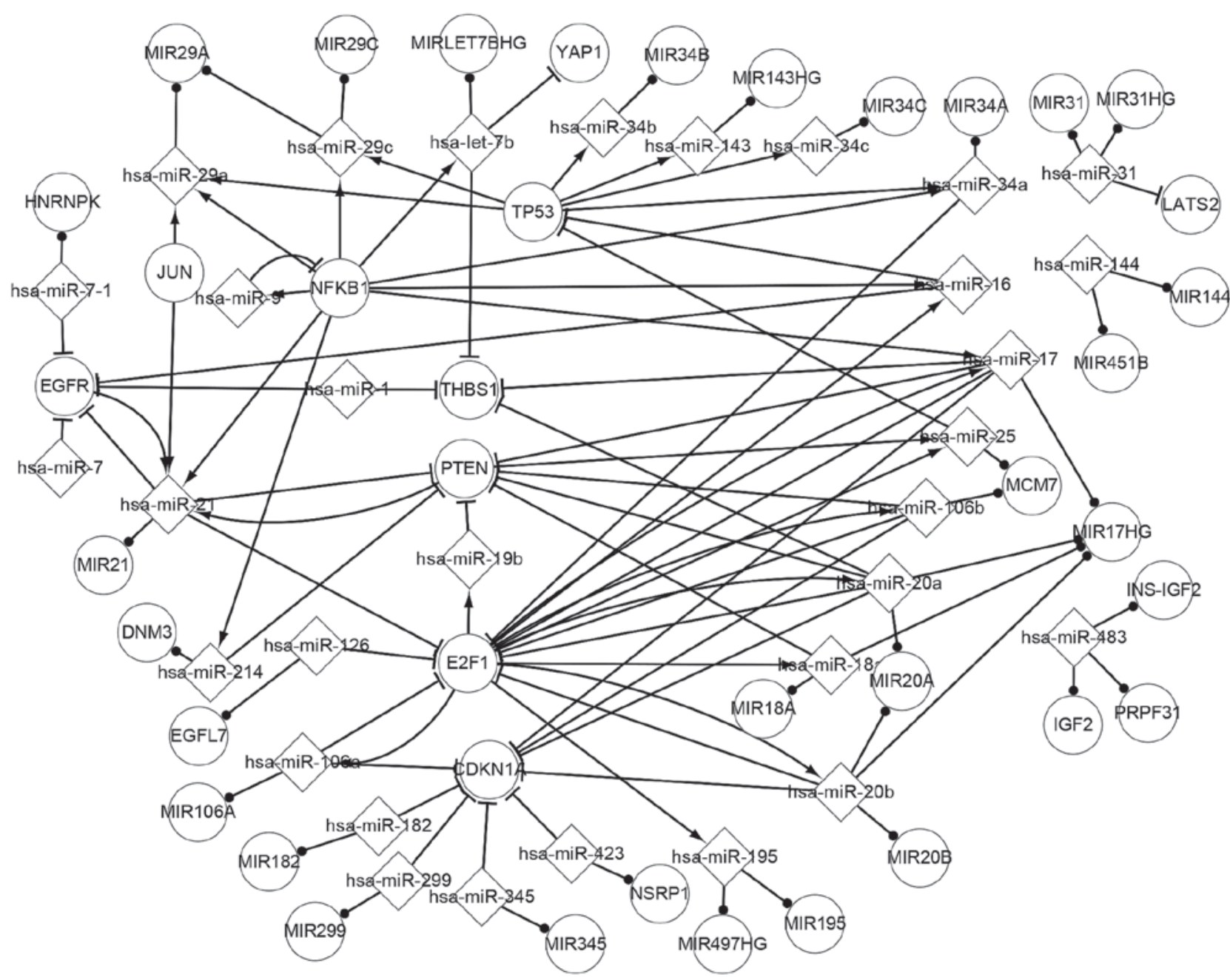

Figure 1. Differentially expressed genes and miRNAs in mesothelioma. miRNA are presented in diamonds, whereas genes are presented in circles. At the end of the lines, arrowheads represent a regulatory relationship, horizontal lines represent a target relationship and circles represent the host relationship.

on one or several genes. For example, hsa-miR-483 is located on insulin-like growth factor 2, INS-IGF2 and pre-mRNA processing factor 31 . The related pathways of the five TFs were demonstrated to be most significant in the core network. For example, hsa-miR-19b targets PTEN, which regulates hsa-miR-21. Hsa-miR-21 targets E2F1, which is also regulated by PTEN. PTEN regulates hsa-miR-21, which targets E2F1. Therefore, this suggests that PTEN may indirectly influence the expression of E2F1. It is interesting to note the feedback loop of PTEN directly regulating hsa-miR-21 and, in turn, hsa-miR-21 targeting PTEN. These regulatory actions may help us to elucidate the pathogenesis of mesothelioma.

Related network of mesothelioma. Fig. 2 presents the related network, consisting of the relevant genes, miRNA and their host genes. The mesothelioma related regulatory network, which also contains the differentially expressed network, is composed of related genes and miRNA, targets and hosts. As compared with Fig. 1, Fig. 2 presents the more complex regulatory relations that influence the progression of mesothelioma. There are seven TFs in the related network, including the five TFs presented in Fig. 1. TP53, PTEN and NFKB1 regulate more miRNA and may be more influential to overexpression in the network than other genes. Notably, NFKB1 regulates the expression of hsa-miR-16, and hsa-miR-16 targets EGFR, TP53, cyclin (CC)E1, aurora kinase B, fibroblast growth factor 2 and NFKB1. Therefore, NFKB1 and hsa-miR-16 constitute a feedback loop.

E2F1 is a important TF which regulates the expression of nine miRNA: hsa-miR-92a, hsa-miR-20a, hsa-miR-20b, hsa-miR-25, hsa-miR-106a, hsa-miR-106b, hsa-miR-16, hsa-miR-18a and hsa-miR-19b. In the related network, 10 feedback loops were detected in total, consisting of five genes and nine miRNA. Five DEGs (TP53, NFKB1, PTEN, EGFR, E2F1) were found to be involved in the feedback loops.

Global network of mesothelioma. The global regulatory network, which is experimentally validated in the human body, contained more information about the mesothelioma (data not shown). As compared with the other two networks, the global network includes all relations in $U_{1}, U_{2}$ and $U_{3}$, and further additional TFs, targets, miRNA and host genes. The global regulatory network contains these two networks. As the data is too vast, we were unable to provide a figure.

Comparison and analysis about feature of DEGs. The pathways of 31 DEGs were extracted and compared. According to the various types of adjacent nodes in regulatory relationships, 


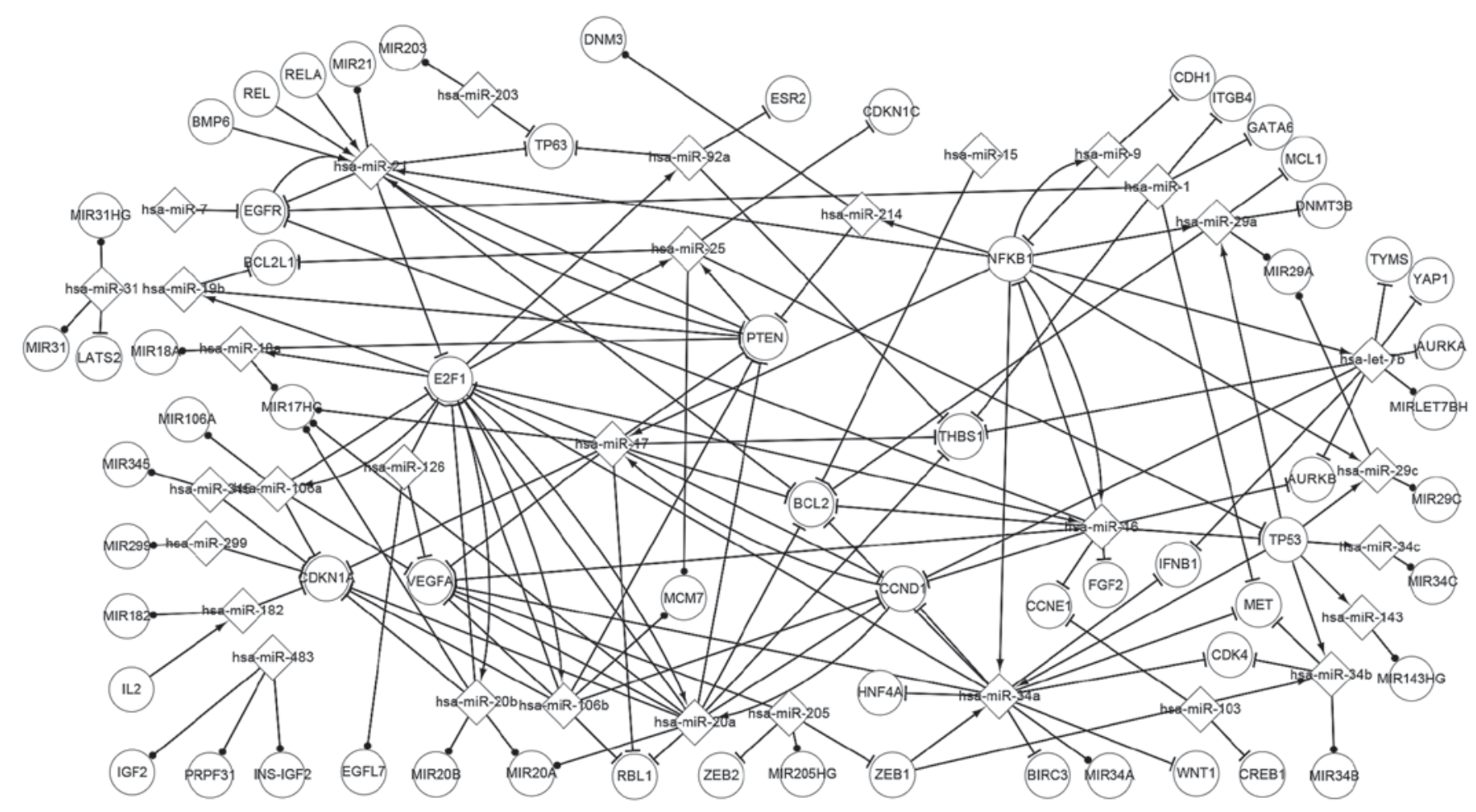

Figure 2. Related genes and miRNAs in mesothelioma. miRNA are presented in diamonds, whereas genes are presented in circles. At the end of the lines, arrowheads represent a regulatory relationship, horizontal lines represent a target relationship and circles represent the host relationship.

DEGs were classified into three level networks to analyze their interacting features. Taking these DEGs into account, E2F1, PTEN and EGFR exhibited the feature of regulating miRNA and being targeted by miRNA in turn.

Upstream miRNA that target E2F1 and downstream miRNA that are regulated by E2F1 are listed in Table I, which shows E2F1, predecessors of E2F1 and successors of E2F1, and their regulatory relations. Notable features were demonstrated in the three networks. Eight miRNA target E2F1 and E2F1 regulates 10 miRNA in the core network, which is consistent with the related network; whereas the global network demonstrated that 17 miRNA target E2F1 and E2F1 regulates 27 miRNA. These predecessors indirectly influence the successors through E2F1. In all the relationships identified, it was demonstrated that hsa-miR-106a, hsa-miR-106b, hsa-miR-20a, hsa-miR-20b and hsa-miR-17 target E2F1 and E2F1 regulates them in the three networks. These miRNA respectively form a self-adaptation function. All are differentially expressed in mesothelioma. Therefore, we hypothesize that these miRNA are of great importance to the progression of mesothelioma.

Our findings demonstrated that the remaining genes are only targeted by certain miRNA, and they do not regulate any miRNA, such as thrombospondin 1 (THBS1) and cyclin dependent kinase inhibitor 1A (CDKN1A). It was suggested that they may be the last node in the pathway. The second type of gene has one type of adjacency node in three networks (a kind of predecessor), including YAP1, LASTS and ACTR1A, which suggested that they have the least influence, as compared with other DEGs. The final class of genes had no adjacent nodes, including RTL1 and LRP1.
Comparison and analysis of the features of differentially expressed miRNA. Each differentially expressed miRNA was considered in the same manner. Six types of miRNA were classified, with a total of 59 differentially expressed miRNA. Seven differentially expressed miRNA (hsa-miR-106a, hsa-miR-20a, hsa-miR-106b, hsa-miR-20b, hsa-miR-17, hsa-miR-9 and hsa-miR-21) exhibited a self-adaptation relationship with their corresponding genes, meaning that each miRNA targets TFs and is, in turn, regulated by them. The six types of miRNA included five miRNA, 20 miRNA, 26 miRNA, 15 miRNA, 15 miRNA and nine miRNA.

The first class of miRNA included six types of adjacency nodes (three predecessors and three successors), including hsa-miR-20a and hsa-miR-34a. The genes that regulated hsa-miR-20a in the upstream and the genes that are targeted by hsa-miR-20a are listed in Table II, which shows hsa-miR-20a predecessors and successors and their regulatory associations. As demonstrated in Table II, E2F1 regulates hsa-miR-20a and simultaneously targets four genes in the differentially expressed network. In the related network, two genes regulate hsa-miR-20a and hsa-miR-20a targets seven genes; whereas ten genes regulate hsa-miR-20a and 25 genes are targeted by hsa-miR-20a in the global network. In the differentially expressed network, E2F1 indirectly influenced the expression of PTEN, THBS1, E2F1 and CDKN1A through the regulation of hsa-miR-20a. As outlined in Table II, E2F1 and hsa-miR-20a form a self-adaptation relationship. It was also demonstrated in the present study that hsa-miR-20a indirectly influences other miRNA via TFs. For example, hsa-miR-20a targets PTEN, which also regulates hsa-miR-21. 
Table I. Regulatory relationship between E2F1 and miRNAs.

\begin{tabular}{|c|c|c|c|c|c|c|}
\hline \multicolumn{3}{|c|}{ miRNAs that target E2F1 } & \multirow[b]{2}{*}{ Gene } & \multicolumn{3}{|c|}{ E2F1-regulated miRNAs } \\
\hline $\begin{array}{l}\text { Differentially } \\
\text { expressed network }\end{array}$ & $\begin{array}{l}\text { Related } \\
\text { network }\end{array}$ & $\begin{array}{l}\text { Global } \\
\text { network }\end{array}$ & & $\begin{array}{c}\text { Differentially } \\
\text { expressed network }\end{array}$ & $\begin{array}{l}\text { Related } \\
\text { network }\end{array}$ & $\begin{array}{l}\text { Global } \\
\text { network }\end{array}$ \\
\hline $\begin{array}{l}\text { miR-106a } \\
\text { miR-106b } \\
\text { miR-126 } \\
\text { miR-17 } \\
\text { miR-20a } \\
\text { miR-20b } \\
\text { miR-21 } \\
\text { miR-34 }\end{array}$ & $\begin{array}{l}\text { miR-106a } \\
\text { miR-106b } \\
\text { miR-126 } \\
\text { miR-17 } \\
\text { miR-20a } \\
\text { miR-20b } \\
\text { miR-21 } \\
\text { miR-34 }\end{array}$ & $\begin{array}{l}\text { miR-7a-1 } \\
\text { miR-7a-2 } \\
\text { miR-7a-3 } \\
\text { miR-106a } \\
\text { miR-149 } \\
\text { miR-17 } \\
\text { miR-21 } \\
\text { miR-23b } \\
\text { miR-34a } \\
\text { miR-106b } \\
\text { miR-126 } \\
\text { miR-20a } \\
\text { miR-223 } \\
\text { miR-330 } \\
\text { miR-93 } \\
\text { miR-98 } \\
\text { miR-20b }\end{array}$ & $\mathrm{E} 2 \mathrm{~F} 1$ & $\begin{array}{l}\text { miR-106a } \\
\text { miR-106b } \\
\text { miR-16 } \\
\text { miR-17 } \\
\text { miR-18a } \\
\text { miR-195 } \\
\text { miR-196 } \\
\text { miR-20a } \\
\text { miR-20b } \\
\text { miR-25 }\end{array}$ & $\begin{array}{l}\text { miR-106a } \\
\text { miR-106b } \\
\text { miR-16 } \\
\text { miR-17 } \\
\text { miR-18a } \\
\text { miR-195 } \\
\text { miR-196 } \\
\text { miR-20a } \\
\text { miR-20b } \\
\text { miR-25 }\end{array}$ & $\begin{array}{l}\text { miR-7a-1 } \\
\text { miR-7a-2 } \\
\text { miR-7a-3 } \\
\text { miR-106a } \\
\text { miR-15a } \\
\text { miR-15b } \\
\text { miR-17 } \\
\text { miR-195 } \\
\text { miR-19a } \\
\text { miR-106b } \\
\text { let-7b } \\
\text { miR-16-1 } \\
\text { miR-16-2 } \\
\text { miR-18a } \\
\text { miR-18b } \\
\text { miR-19b-1 } \\
\text { miR-19b-2 } \\
\text { miR-20a } \\
\text { miR-20b } \\
\text { miR-223 } \\
\text { miR-25 } \\
\text { miR-363 } \\
\text { miR-449a } \\
\text { miR-449c } \\
\text { miR-92a-1 } \\
\text { miR-92a-2 } \\
\text { miR-93 }\end{array}$ \\
\hline
\end{tabular}

The second class of miRNA included five types of adjacency nodes (three successors and two predecessors, two successors and three predecessors), including hsa-miR-182. In the differentially expressed network, no gene was found to regulate hsa-miR-182, whereas hsa-miR-182 targets CDKN1A. In the related network, IL2 regulates hsa-miR-182 and hsa-miR-182 targets CDKN1A.

The third class of miRNA included four types of adjacency nodes, which were composed of three successors and one predecessor, two successors and two predecessors, one successor and three predecessors, including hsa-miR-106a, hsa-miR-214, hsa-miR-9, hsa-miR-126 and hsa-miR-7. In the differentially expressed and related networks, no TF was found to regulate hsa-miR-7 and hsa-miR-7 targets EGFR. It was demonstrated that three genes regulate hsa-miR-7 and hsa-miR-7 targets 50 genes in the global network.

The fourth class of miRNA included three types of adjacency nodes (three successors, two successors and one predecessor, one successor and two predecessors), including hsa-miR-345 and hsa-miR-301a. No gene was found to regulate hsa-miR-345 in the three networks; whereas hsa-miR-345 targets CDKN1A in the differentially expressed and related networks and hsa-miR-345 targets three genes in the global network. These findings show that there is no gene that indirectly influences the expression of other genes by regulating hsa-miR-345 in the three networks. In the related network, hsa-miR-301a is regulated by IL6 and simultaneously targets MEOX2, NKRF and SERPINE1 in the global network.

The fifth class of miRNA included two types of adjacency nodes (two successors or one successor and one predecessor), including hsa-miR-30c. EGR1 regulates hsa-miR-30c in the global network, and hsa-miR-30c targets UBE2I, MUC17 and SERPINE1 in the global network.

The sixth class of miRNA included one type of adjacency node, which was a successor, such as hsa-miR-584. There was no gene identified that regulated hsa-miR-584 in the three networks and hsa-miR-584 only targets ROCK1 in the global network.

Comparison and analysis of the features of popular TFs. The same method was used to compare and analyze each popular TF in related network. Three TFs (CCND1, ZEB2 and ZEB1) 
Table II. Regulatory relationship between hsa-miR-20a and genes.

Genes that regulate miR-20a

\begin{tabular}{|c|c|c|c|c|c|c|}
\hline $\begin{array}{l}\text { Differentially } \\
\text { expressed network }\end{array}$ & $\begin{array}{l}\text { Related } \\
\text { network }\end{array}$ & $\begin{array}{c}\text { Global } \\
\text { network }\end{array}$ & miRNA & $\begin{array}{c}\text { Differentially } \\
\text { expressed network }\end{array}$ & $\begin{array}{l}\text { Related } \\
\text { network }\end{array}$ & $\begin{array}{c}\text { Global } \\
\text { network }\end{array}$ \\
\hline $\mathrm{E} 2 \mathrm{~F} 1$ & $\begin{array}{l}\text { E2F1 } \\
\text { CCND1 }\end{array}$ & $\begin{array}{l}\text { E2F1, } \\
\text { MYC, } \\
\text { MYCN, } \\
\text { NKX2-5, } \\
\text { TLX1, } \\
\text { TLX3, } \\
\text { ERS1, } \\
\text { STAT5, } \\
\text { SPI, } \\
\text { CCND1 }\end{array}$ & miR-20a & $\begin{array}{l}\text { CDKN1A, } \\
\text { E2F1, } \\
\text { PTEN, } \\
\text { THBS1 }\end{array}$ & $\begin{array}{l}\text { E2F1, CDKN1APTEN, } \\
\text { BCL2, THBS1, RBL1, } \\
\text { VEGFA }\end{array}$ & $\begin{array}{l}\text { BCL2, BMPR2, } \\
\text { BNIP2, CCND1, } \\
\text { CCND2, E2F1, } \\
\text { E2F3, HIF1A, } \\
\text { MAP3K12, MYC, } \\
\text { MEF2D, MUC17, } \\
\text { NRAS, PTEN, } \\
\text { RB1, RBL1, } \\
\text { RBL2, RUNX1, } \\
\text { SMAD4, THBS1, } \\
\text { TGFBR2, APP, } \\
\text { VEGFR, WEE1 }\end{array}$ \\
\hline
\end{tabular}

Table III. Regulatory relationship between CCND1 and miRNAs.

\begin{tabular}{|c|c|c|c|c|c|c|}
\hline \multicolumn{3}{|c|}{ miRNAs that target CCND1 } & \multirow[b]{2}{*}{ Gene } & \multicolumn{3}{|c|}{ CCND1-regulated miRNAs } \\
\hline $\begin{array}{l}\text { Differentially } \\
\text { expressed network }\end{array}$ & $\begin{array}{l}\text { Related } \\
\text { network }\end{array}$ & $\begin{array}{c}\text { Global } \\
\text { network }\end{array}$ & & $\begin{array}{c}\text { Differentially } \\
\text { expressed network }\end{array}$ & $\begin{array}{l}\text { Related } \\
\text { network }\end{array}$ & $\begin{array}{r}\text { Global } \\
\text { network }\end{array}$ \\
\hline $\begin{array}{l}\text { miR-16 } \\
\text { miR-106b } \\
\text { miR-20a } \\
\text { miR-34a }\end{array}$ & $\begin{array}{l}\text { miR-106b } \\
\text { miR-16 } \\
\text { miR-20a } \\
\text { miR-34 }\end{array}$ & $\begin{array}{l}\text { miR-106b, miR-15a } \\
\text { miR-15b, miR-16 } \\
\text { miR-16-1 }{ }^{*}, \text { miR-17 } \\
\text { miR-193a, miR-19 } \\
\text { miR-20a, miR-302a } \\
\text { miR-302c, miR-424 } \\
\text { miR-34a, let-7b } \\
\text { miR-449a, miR-503 }\end{array}$ & CCND1 & $\begin{array}{l}\text { miR-17 } \\
\text { miR-20a }\end{array}$ & $\begin{array}{l}\operatorname{miR}-17 \\
\text { miR-20a }\end{array}$ & $\begin{array}{l}\text { miR-17 } \\
\text { miR-20a }\end{array}$ \\
\hline
\end{tabular}

and their corresponding miRNA were demonstrated to form respective self-adaptation relationships.

The first class of TF included six types of adjacent nodes (three successors and three predecessors), including CCND1 and ZEB2. Table III shows CCND1, its predecessors and successors, and their regulatory relations. Four differentially expressed miRNA target CCND1 and CCND1 simultaneously regulates two differentially expressed miRNA. In the global network, 16 miRNA target CCND1 and CCND1 regulates two miRNA. It was demonstrated that hsa-miR-20a and CCND1 respectively form a self-adaptation relationship. Although hsa-miR-20a is differentially expressed in mesothelioma, CCND1 is not. This suggests that CCND1 indirectly leads to the expression of other miRNA in error. The pathways associated with CCND1 and differentially expressed miRNA indicated additional differentially expressed miRNA in mesothelioma. These miRNA are not only differentially expressed, but are also adjacent nodes of CCND1 that are frequently associated with transcription in cancerous tissues. Furthermore, ZEB1 is targeted by hsa-miR-20 and ZEB1 simultaneously regulates hsa-miR-34a and hsa-miR-34b in the differentially expressed network. In the global network, six miRNA target ZEB1 and ZEB1 regulates eight miRNA.

The second class of TF included four types of adjacent nodes (one successor and three predecessors), including ZEB2. ZEB2 is targeted by hsa-miR-205 and ZEB2 does not regulate any differentially expressed miRNA. In the global network, seven miRNA target ZEB2, which regulates five miRNA.

Analysis of host genes and their miRNA in mesothelioma. In the present study, significant features were detected in the association between host genes and their miRNA. These host genes as DEGs in mesothelioma when their miRNA were differentially expressed. Notably, they also influence the progression of mesothelioma. Fig. 3 outlines some of the differentially expressed miRNA and corresponding host gene pathways. A host gene may include numerous miRNA that can target other genes alone or together. Various notable relations were detected between host genes and other elements 


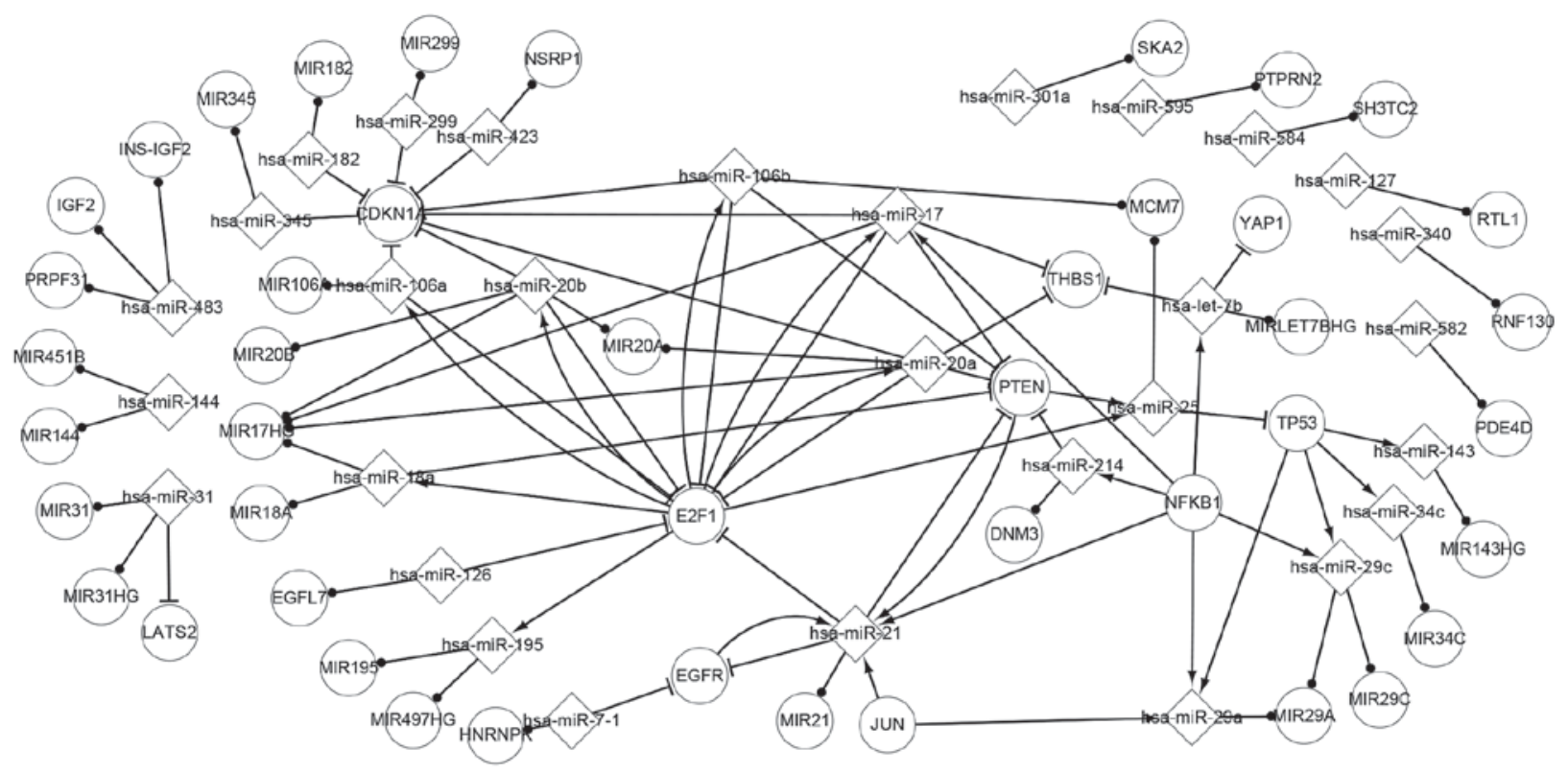

Figure 3. Significantly related miRNAs and their host genes. miRNA are presented in diamonds, whereas genes are presented in circles. At the end of the lines, arrowheads represent a regulatory relationship, horizontal lines represent a target relationship and circles represent the host relationship.

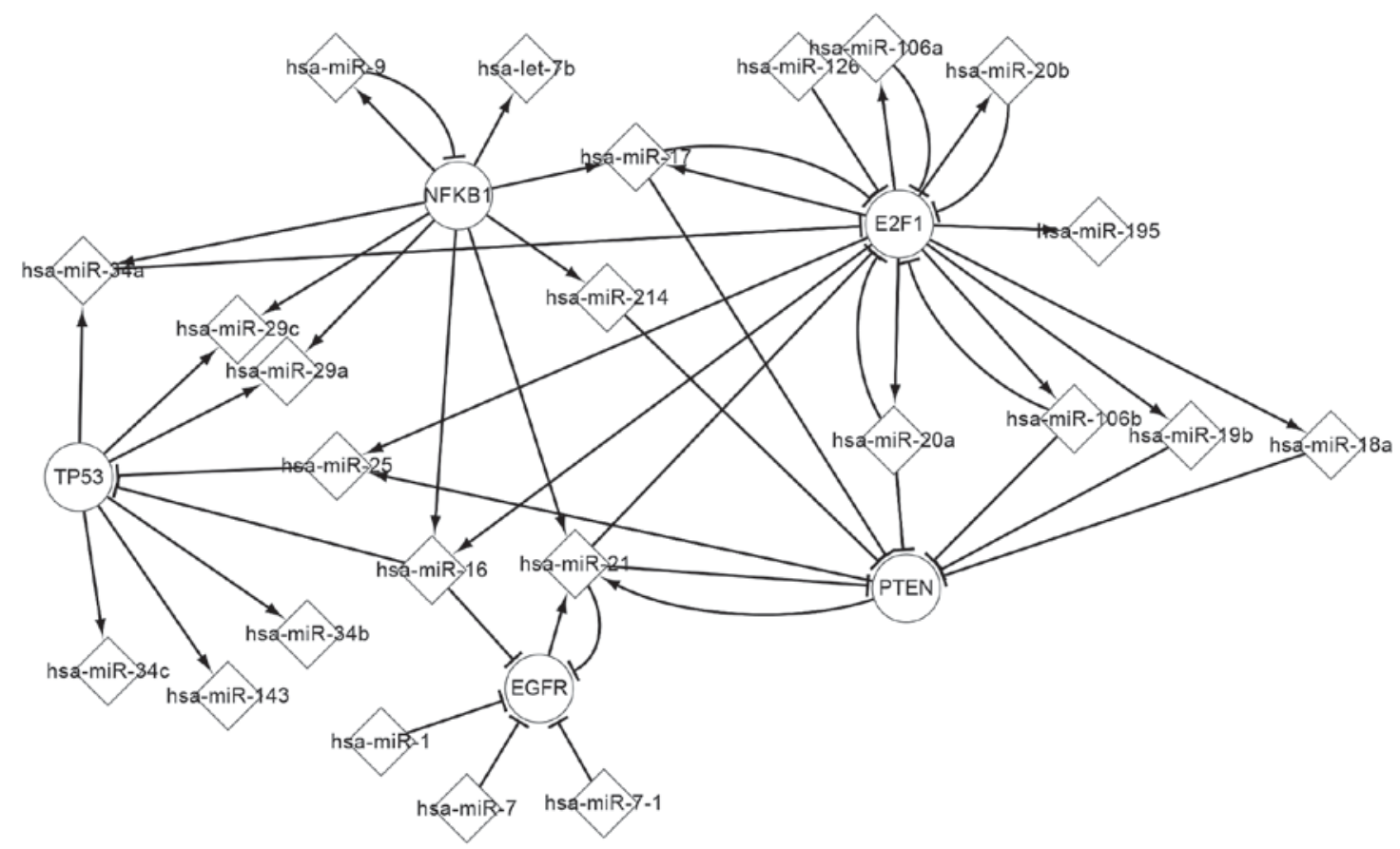

Figure 4. Network of transcription factors and differentially expressed miRNAs. miRNA are presented in diamonds, whereas genes are presented in circles. At the end of the lines, arrowheads represent a regulatory relationship, horizontal lines represent a target relationship and circles represent the host relationship.

in Fig. 1. MIR17HG includes four miRNA (hsa-miR-20a, hsa-miR-17, hsa-miR-18a and hsa-miR-20b) that together target E2F1. EGFR and NFKB1 regulate hsa-miR-21. MCM7 includes two miRNA (hsa-miR-25 and hsa-miR-106b) that are regulated by E2F1, and also target PTEN and E2F1. THBS1 is targeted by four miRNA (hsa-let-7b, hsa-miR-1, hsa-miR-20a and hsa-miR-17) but does not regulate any miRNA. These findings suggest that host genes and their miRNA may be useful for the elucidation of the regulatory mechanism of mesothelioma.
Transcriptional network of TFs and differentially expressed miRNA. Figure 4 shows the transcriptional network of popular TFs and differentially expressed miRNA. A total of 49 miRNA were found to be differentially expressed in mesothelioma. However, 24 differentially expressed miRNA with regulatory relations with the popular TFs were subsequently analyzed. It was demonstrated that TFs and miRNA influence their successors; therefore, they may have pivotal roles in the progression of mesothelioma. Figure 3 shows that NFKB1, TP53, E2F1, PTEN and EGFR are more connected than other 
TFs. These TFs and differentially expressed miRNA interact with each other to affect the progression of mesothelioma. The present findings demonstrated that one differentially expressed miRNA can be regulated by several TFs For example, hsa-miR-25 is regulated by E2F1 and PTEN. One TF can also be targeted by several differentially expressed miRNA, as EGFR is targeted by hsa-miR-16, hsa-miR-21, hsa-miR-1, hsa-miR-7 and hsa-miR-7-1. In addition, one TF can indirectly influence another TF via differentially expressed miRNA, as E2F1 is able to affect PTEN through hsa-miR-20a, and one differentially expressed miRNA can indirectly influence another miRNA by TF, as hsa-miR-17 targets PTEN which simultaneously regulates hsa-miR-25 and hsa-miR-21. The regulatory relations of popular TFs and miRNA will aid further comprehension of the pathogenesis of mesothelioma.

In the present study, three regulatory networks were established, differentially expressed, related and global, after comparing and analyzing all experimentally validated genes and miRNA associated with mesothelioma to date. DEGs and miRNA have been demonstrated to have key roles in the three networks, and they participate in cancer progression via carcinogenesis, metastasis and therapy (24). Pathways were investigated in order to aid the elucidation of the pathogenesis of mesothelioma. Some pathways exhibited special features. For example, five popular TFs (E2F1, EGFR, NFKB1, PTEN and TP53) and seven differentially expressed miRNA (hsa-miR-106a, hsa-miR-106b, hsa-miR-20a, hsa-miR-20b hsa-miR-9, hsa-miR-21 and hsa-miR-17) form seven self-adaptation relationships, which suggests that some genes act as key regulators in the expression of other genes and miRNA.

These results and the comprehensive data supplied may contribute to the elucidation of the carcinogenicity mechanism and therapy of mesothelioma. Further research is required to investigate the remaining pathways associated with mesothelioma. Future studies should consider transcription co-factors and the interaction of proteins in mesothelioma in our network in order to form a more complex and extensive network. These extensive data may help to elucidate the pathogenesis and novel treatments for mesothelioma.

\section{Acknowledgements}

The present study was supported by grants from the National Natural Science Foundation of China (grant no. 60973091) and the Science and Technology Development Plan of Jilin Province (grant no. 20130101166JC).

\section{References}

1. Mesaros C, Worth AJ, Snyder NW, Christofidou-Solomidou M, Vachani A, Albelda SM and Blair IA: Bioanalytical techniques for detecting biomarkers of response to human asbestos exposure. Bioanalysis 7: 1157-1173, 2015.

2. Churg A and Wiggs B: Fiber size and number in amphibole asbestos-induced mesothelioma. Am J Pathol 115: 437-442, 1984.

3. Bartel DP: MicroRNAs: Target recognition and regulatory functions. Cell 136: 215-233, 2009.

4. Yang H, Testa JR and Carbone M: Mesothelioma epidemiology, carcinogenesis, and pathogenesis. Curr Treat Options Oncol 9: 147-157, 2008.
5. Chen Y and Stallings RL: Differential patterns of microRNA expression in neuroblastoma are correlated with prognosis, differentiation, and apoptosis. Cancer Res 67: 976-983, 2007.

6. Hobert O: Gene regulation by transcription factors and microRNAs. Science 319: 1785-1786, 2008.

7. Kim OY, Cha HJ, Ahn KJ, An IS, An S and Bae S: Identification of microRNAs involved in growth arrest and cell death in hydrogen peroxide-treated human dermal papilla cells. Mol Med Rep 10: 145-154, 2014.

8. Huang S, He X, Ding J, Liang L, Zhao Y, Zhang Z, Yao X, Pan Z, Zhang P, Li J, et al: Upregulation of miR-23a approximately 27 a approximately 24 decreases transforming growth factor-beta-induced tumor-suppressive activities in human hepatocellular carcinoma cells. Int J Cancer 123: 972-978, 2008.

9. O'Donnell KA, Wentzel EA, Zeller KI, Dang CV and Mendell JT: c-Myc-regulated microRNAs modulate E2F1 expression. Nature 435: 839-843, 2005.

10. Wu D, Ozaki T, Yoshihara Y, Kubo N and Nakagawara A: Runt-related transcription factor 1 (RUNX1) stimulates tumor suppressor p53 protein in response to DNA damage through complex formation and acetylation. J Biol Chem 288: 1353-1364, 2013.

11. Zou C, Li Y, Cao Y, Zhang J, Jiang J, Sheng Y, Wang S, Huang A and Tang H: Up-regulated microRNA-181a induces carcinogenesis in hepatitis B virus-related hepatocellular carcinoma by targeting E2F5. BMC Cancer 14: 97, 2014.

12. Balatti V, Maniero S, Ferracin M, Veronese A, Negrini M, Ferrocci G, Martini F and Tognon MG: MicroRNAs dysregulation in human malignant pleural mesothelioma. J Thorac Oncol 6: 844-851, 2011.

13. Ramírez-Salazar EG, Salinas-Silva LC, Vázquez-Manríquez ME, Gayosso-Gómez LV, NegreteGarcia MC, Ramírez-Rodriguez SL, Chávez R, Zenteno E, Santillán P, Kelly-García J and Ortiz-Quintero B: Analysis of microRNA expression signatures in malignant pleural mesothelioma, pleural inflammation, and atypical mesothelial hyperplasia reveals common predictive tumorigenesis-related targets. Exp Mol Pathol 97: 375-385, 2014.

14. Rodriguez A, Griffiths-Jones S, Ashurst JL and Bradley A: Identification of mammalian microRNA host genes and transcription units. Genome Res 14: 1902-1910, 2004.

15. Baskerville S and Bartel DP: Microarray profiling of microRNAs reveals frequent coexpression with neighboring miRNAs and host genes. RNA 11: 241-247, 2005

16. Safran M, Dalah I, Alexander J, Rosen N, Iny Stein $T$, Shmoish M, Nativ N, Bahir I, Doniger T, Krug H, et al: GeneCards version 3: The human gene integrator. Database (Oxford) 2010: baq020, 2010.

17. Chekmenev DS, Haid C and Kel AE: P-Match: Transcription factor binding site search by combining patterns and weight matrices. Nucleic Acids Res 33 (Web Server Issue): W432-W437, 2005.

18. Fujita PA, Rhead B, Zweig AS, Hinrichs AS, Karolchik D, Cline MS, Goldman M, Barber GP, Clawson H, Coelho A, et al: The UCSC genome browser database: Update 2011. Nucleic Acids Res 39 (Database Issue): D876-D882, 2011.

19. Jiang Q, Wang Y, Hao Y, Juan L, Teng M, Zhang X, Li M, Wang G and Liu Y: miR2Disease: A manually curated database for microRNA deregulation in human disease. Nucleic Acids Res 37 (Database Issue): D98-D104, 2009.

20. Wang J, Lu M, Qiu C and Cui Q: TransmiR: A transcription factor-microRNA regulation database. Nucleic Acids Res 38: D119-D122, 2009.

21. Kozomara A and Griffiths-Jones S: miRBase: Integrating microRNA annotation and deep-sequencing data. Nucleic Acids Res 39 (Database Issue): D152-D157, 2011.

22. de Assis LV and Isoldi MC: The function, mechanisms, and role of the genes PTEN and TP53 and the effects of asbestos in the development of malignant mesothelioma: A review focused on the genes' molecular mechanisms. Tumour Biol 35: 889-901, 2014.

23. Morris MR and Maher ER: Epigenetics of renal cell carcinoma: The path towards new diagnostics and therapeutics. Genome Med 2: 897-910, 2010.

24. Tran DH, Satou K, Ho TB and Pham TH: Computational discovery of miR-TF regulatory modules in human genome. Bioinformation 8: 371-377, 2010. 